\title{
Interação de Imazapic no Sistema Integrado Palha de Cana-de- AÇÚCAR, HeRbicida E VinhaÇa NO CRESCIMENTO INICIAL DA TIRIRICA ${ }^{1}$
}

\author{
Interaction of Imazapic in the Integrated System Using Sugarcane Mulch Residue, Herbicide and \\ Vinasse on Purple Nutsedge Growth
}

\author{
NOVO, M.C.S.S. ${ }^{2}$, VICTORIA FILHO, R. ${ }^{3}$, LANGBECK, F.M. ${ }^{4}$, LAGO, A.A. ${ }^{2}$, DEUBER, R. ${ }^{2}$ \\ e ROLIM, G.S. ${ }^{2}$
}

\begin{abstract}
RESUMO - O objetivo deste trabalho foi avaliar o efeito da interação palha de cana-deaçúcar, herbicida imazapic e diferentes meios de aplicação de vinhaça no crescimento inicial da tiririca. O experimento foi realizado em casa de vegetação e em vasos dispostos em blocos ao acaso com quatro repetições, sendo avaliados os tratamentos: controle; apenas palha; apenas vinhaça; apenas o herbicida imazapic; palha + vinhaça; palha + herbicida; herbicida + vinhaça aplicada antes do herbicida; herbicida + vinhaça aplicada depois do herbicida; herbicida + vinhaça aplicada junto com o herbicida em mistura; palha + herbicida + vinhaça aplicada antes do herbicida; palha + herbicida + vinhaça aplicada depois do herbicida; e palha + herbicida + vinhaça aplicada junto com o herbicida em mistura. O imazapic foi aplicado na dose de $122,5 \mathrm{~g} \mathrm{ha}^{-1} \mathrm{e}$, no tratamento onde a vinhaça foi aplicada em mistura com o herbicida, este foi diluído com água até 1/4 do volume necessário e completado com vinhaça. O imazapic foi eficiente no controle da tiririca quando comparado com a testemunha. A aplicação isolada da vinhaça ou a adição de apenas a palha ao solo estimularam o crescimento da tiririca embora tenha reduzido a viabilidade dos tubérculos. Nos tratamentos sem palha, não houve diferença no crescimento da tiririca, quando a aplicação de vinhaça foi realizada antes ou depois do imazapic, sendo observado controle da espécie. Entretanto, quando em mistura com a vinhaça, o produto não controlou a tiririca. A presença da palha no tratamento onde foi aplicada vinhaça antes do herbicida reduziu a ação do imazapic, em comparação com aquele sem palha. O número de brotações e a altura média de plantas de tiririca foram maiores nos tratamentos com palha quando foi aplicado imazapic depois ou mesmo junto com a vinhaça. Sob palha, a aplicação de vinhaça após o herbicida ou em mistura com imazapic aumentou apenas o número de brotações.
\end{abstract}

Palavras-chave: aril triazolinona, cana-crua, Cyperus rotundus L., imidazolinona.

\begin{abstract}
The objective of this paper was to evaluate sugarcane mulch residue, imazapic and vinasse application interaction on the initial development of purple nutsedge (Cyperus rotundus L.). A greenhouse experiment was set up using pots filled with soil, arranged in a randomized complete blocks design, with four replications, with the following treatments: check; straw alone; vinasse alone; imazapic alone; straw + vinasse; straw + herbicide; herbicide + vinasse applied before the herbicide; herbicide + vinasse applied together; straw + herbicide + vinasse applied after the herbicide; straw + herbicide + vinasse applied after the herbicide; and straw + herbicide + vinasse applied together. Imazapic was applied at the rate of $122.5 \mathrm{~g} \mathrm{ha}^{-1}$ and in the treatment in which vinasse was applied mixed with the herbicide, this compound was diluted in water until $1 / 4$ of the volume needed, the remaining volume being completed with vinasse. Imazapic was efficient for purple nutsedge control when compared to the check. Application of vinasse alone or straw alone stimulated the growth of this weed, though tuber viability was reduced. In the treatments
\end{abstract}

1 Recebido para publicação em 13.3.2007 e na forma revisada em 20.3.2008.

2 Pesquisador Científico, Instituto Agronômico, Caixa Postal 970, Campinas-SP, <jpsnovo@iac.sp.gov.br>;3 Professor Titular, ESALQ/USP, Caixa Postal 9, 13418-900, Piracicaba-SP, <rvictori@esalq.usp.br>;4 Acadêmico de Ciências Biológicas, PUC Campinas, Campinas-SP.

Planta Daninha, Viçosa-MG, v. 26, n. 2, p. 439-449, 2008 
without straw there was no difference in purple nutsedge development when vinasse was applied before or after imazapic, though control of this weed species was attained. However, when mixed with vinasse, the herbicide did not control the weed. The presence of straw in the treatment in which vinasse was applied before imazapic reduced the action of this weed killer when compared with the treatment without straw. The number of sprouts and height of the purple nutsedge plants were enhanced by the treatments with straw when imazapic was applied after or even mixed with vinasse. Only the number of sprouts increased when vinasse was applied after or mixed with the herbicide in soil covered with straw.

Keywords: aril triazolinone, unburned sugarcane, Cyperus rotundus L., imidazolinone.

\section{INTRODUÇÃO}

Em diversas regiões do Brasil, a palhada de cana-de-açúcar (Saccharum spp.) tem sido eliminada dos canaviais por meio do fogo, visando, principalmente, facilitar as operações de corte e carregamento dos toletes e baratear o custo do corte manual. Entretanto, por estar associado a impactos ambientais, à segurança e ao bem-estar da população, o uso do fogo com essa finalidade foi restringido por força legal no Estado de São Paulo, devendo ser eliminado completamente até 2031 (São Paulo, 2003). Em contrapartida, a eliminação gradativa do uso do fogo vem promovendo a mecanização do sistema de colheita de cana-de-açúcar, chamado de cana-verde ou cana-crua.

A colheita mecanizada da cana-de-açúcar deixa sobre o solo uma camada de palha que, dependendo das condições edafoclimáticas e dos cultivares utilizados, pode ser superior a 20 t ha $^{-1}$ (Velini \& Negrisoli, 2000). A palha depositada sobre o solo forma uma camada, que pode alcançar de 0,08 a $0,10 \mathrm{~m}$ de espessura, causando alterações na comunidade de plantas daninhas presente na área. Algumas espécies daninhas têm seu fluxo de emergência reduzido quando a densidade de cobertura morta é maior que $300 \mathrm{~g} \mathrm{~m}^{-2}$ e a porcentagem de recobrimento do solo for superior a $90 \%$ (Voll, 2005). Esse efeito é devido a modificações nas condições químicas, físicas e biológicas do ambiente agrícola (Blevins et al., 1971). A presença de palha no ambiente afeta a brotação e o crescimento das plantas, por influenciar processos como dormência, germinação, mortalidade das sementes e o estabelecimento e reprodução das plantas (Trezzi \& Vidal, 2004). Segundo
Naquin (2005), a palha deixada sobre o solo afeta também a ação dos herbicidas, pois interfere nos processos de volatilização, degradação e absorção dos herbicidas, podendo reduzir o controle das espécies daninhas.

A tiririca (Cyperus rotundus) é uma das principais infestantes dos canaviais, sendo considerada por Holm et al. (1977) uma das plantas mais nocivas às culturas. No sistema cana-crua, seu desenvolvimento é afetado pela adição de palha ao solo, ocorrendo redução no número de brotações, na área foliar e nas biomassas frescas e secas das folhas e da parte aérea total (Novo et al., 2005).

Como as plantas daninhas são um dos pontos criticos no estabelecimento da cultura da cana-de-açúcar, há grande demanda por recursos financeiros para seu controle, sendo a maior parte investida em herbicidas (Quintela et al., 2002). Na cultura da cana-de-açúcar são usados diversos herbicidas, sendo os mais empregados aqueles de aplicação em pré-emergência (Medeiros, 2001). Entretanto, um programa integrado de controle dessas espécies ainda é a melhor opção (Gomide, 1993).

O imazapic é um herbicida registrado no Brasil para controle de espécies daninhas nas áreas de plantio e soqueira em cana-de-açúcar; ele controla a tiririca, se a aplicação for realizada quando esta espécie estiver em pleno desenvolvimento vegetativo para que ocorra maior absorção do produto. No Brasil, tem sido aplicado em pré-emergência (Rodrigues \& Almeida, 2005). É fracamente adsorvido em solos com pH elevado, mas a sua adsorção aumenta em condições ácidas e quando os teores de matéria orgânica e argila são mais elevados. 
Contudo, sua sorção é reversivel (Rodrigues \& Almeida, 2005).

Outro produto que pode ser utilizado no controle de espécies daninhas é a vinhaça (Quintela et al., 2002), que é um efluente líquido obtido da destilação do álcool; por possuir alta demanda química por oxigênio, constitui fonte de contaminação de águas superficiais, de lençóis freáticos e do ambiente (Voll, 2005). Para evitar problemas ambientais, a aplicação da vinhaça na cultura da cana-de-açúcar foi adotada pela maioria das usinas produtoras de álcool e açúcar. O teor de nutrientes da vinhaça varia de acordo com o tipo de mosto utilizado na destilaria, sendo considerado tanto um fertilizante orgânico como mineral devido aos elevados teores de matéria orgânica e de potássio (Buss, 1977), podendo substituir adubações se aplicado racionalmente. Com a adição da vinhaça ao solo, ocorre elevação do $\mathrm{pH}$ e do teor de matéria orgânica, aumentando a disponibilidade de alguns nutrientes e o poder de retenção dos cátions, estimulando a atividade microbiana (Quintela et al., 2002). Segundo os mesmos autores, a vinhaça pode ser utilizada no controle de daninhas por ser constituída por diversos ácidos orgânicos e alterar a quantidade, o fluxo de emergência destas espécies e a ação dos herbicidas.

Christoffoleti \& Bacchi (1985) avaliaram o efeito de doses de vinhaça sobre a incidência de plantas daninhas e constataram que as emergências de Digitaria horizontalis, C. rotundus, Sida rhombifolia e Emilia sonchifolia foram menores. A presença da palha na superficie do terreno dificulta o transporte do herbicida até o solo. A aplicação da vinhaça na palhada de cana-de-açúcar pode ter ação de doadora de prótons e, assim, levar o herbicida aplicado até o solo (Rodella \& Ferrari, 1997). Buss \& Silva (1976) verificaram a viabilidade do uso de herbicidas em mistura com vinhaça para controle de plantas daninhas na cultura de cana-de-açúcar e constataram que a eficiência no controle destas espécies foi significativamente aumentada para alguns herbicidas quando misturados com vinhaça, se comparados com métodos tradicionais de aplicação desses produtos.

Há escassez de trabalho no que se refere ao manejo de plantas daninhas usando o sistema integrado com palha, vinhaça e herbicidas na cultura da cana-de-açúcar. O objetivo deste trabalho foi avaliar o efeito da interação palha de cana-de-açúcar, herbicida imazapic e diferentes meios de aplicação da vinhaça no crescimento inicial da tiririca.

\section{MATERIAL E MÉTODOS}

O experimento foi instalado na casa de vegetação do Centro de Ecofisiologia e Biofísica do Instituto Agronômico (IAC), em Campinas, SP, em 25 de outubro de 2003. O solo, um Latossolo Vermelho Escuro, foi coletado na profundidade de até $0,20 \mathrm{~m}$. A terra foi peneirada para retirada de torrões, restos de vegetais e, principalmente, de tubérculos de tiririca e colocada em vasos de plásticos com capacidade para três quilogramas, com furos para percolação da solução do solo. O resultado da análise de fertilidade e granulométrica do solo é apresentado na Tabela 1.

Da mesma área de onde foi retirado o solo, coletaram-se plantas inteiras de tiririca e separaram-se os tubérculos dormentes, com aspecto sadio, que não apresentassem danos físicos e com biomassa fresca média de $0,5 \mathrm{~g}$. Em todos os vasos foram plantados quatro tubérculos de tiririca a $0,03 \mathrm{~m}$ de profundidade. $\mathrm{O}$ herbicida imazapic foi aplicado na dose de $122,5 \mathrm{~g} \mathrm{ha}^{-1}$, com pulverizador costal, com pressão constante de $2,1 \mathrm{kgf} \mathrm{cm}^{-2}$, munido de barra com quatro pontas do tipo leque $80.020 \mathrm{E}$, distanciados entre si de $0,50 \mathrm{~m}$, a 0,50 m de altura da superfície do vaso e com consumo de calda correspondente a $400 \mathrm{~L} \mathrm{ha}^{-1}$. A palha do cultivar SP 801842 proveniente da Usina Costa Pinto, Charqueada, SP, foi adicionada aos tratamentos correspondentes na quantidade equivalente a $15 \mathrm{t} \mathrm{ha}^{-1}$. O teor de umidade da palha por ocasião da instalação do experimento era de $12,92 \%$. O resultado da análise de fertilidade da palha é apresentado na Tabela 1. A vinhaça proveniente dos tanques de armazenamento da Usina Costa Pinto estava na temperatura ambiente e foi aplicada na quantidade correspondente a $150 \mathrm{~m}^{3} \mathrm{ha}^{-1}$. O resultado da análise de fertilidade da vinhaça encontra-se na Tabela 1.

O experimento foi disposto em blocos ao acaso, em casa de vegetação, com doze tratamentos e quatro repetições. Os tratamentos são descritos na Tabela 2. Nos tratamentos em 
Tabela 1 - Análises da fertilidade e granulometria do solo e de fertilidade da palha e da vinhaça. Campinas-SP, 2003

\begin{tabular}{|c|c|c|c|c|c|c|c|c|c|c|c|}
\hline \multicolumn{12}{|c|}{ Solo } \\
\hline \multicolumn{12}{|c|}{ Macronutrientes } \\
\hline P resina & \multirow{2}{*}{$\begin{array}{c}\mathrm{pH} \\
\mathrm{CaCl}_{2}\end{array}$} & $\mathrm{MO}^{1 /}$ & $\mathrm{K}$ & \multicolumn{2}{|c|}{$\mathrm{Ca}$} & \multicolumn{2}{|c|}{$\mathrm{Mg}$} & $\mathrm{H}+\mathrm{Al}$ & $\mathrm{SB}^{1 /}$ & $\mathrm{CTC}^{1}$ & \multirow{2}{*}{$\begin{array}{l}\mathrm{V}^{1 / /} \\
\% \\
\end{array}$} \\
\hline $\mathrm{mg} \mathrm{dm}^{-3}$ & & $\mathrm{~g} \mathrm{dm}^{-3}$ & \multicolumn{8}{|c|}{ 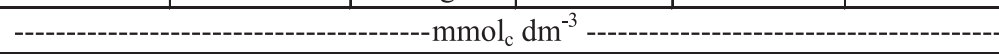 } & \\
\hline 41 & 5,5 & 26 & 3,6 & \multicolumn{2}{|c|}{34} & \multicolumn{2}{|c|}{13} & 22 & 50,6 & 73,1 & 69 \\
\hline \multicolumn{6}{|c|}{ Micronutrientes } & \multicolumn{6}{|c|}{ Granulometria } \\
\hline $\mathrm{B}$ & $\mathrm{Cu}$ & $\mathrm{Fe}$ & $\mathrm{Mn}$ & \multicolumn{2}{|l|}{$\mathrm{Zn}$} & \multicolumn{2}{|c|}{ Areia grossa } & Areia fina & Areia total & Silte & Argila \\
\hline \multicolumn{6}{|c|}{ 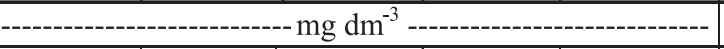 } & \multicolumn{6}{|c|}{-------------------------------------- ${ }^{-}$} \\
\hline 0,39 & 1,3 & 10 & 44,2 & \multicolumn{2}{|l|}{2,0} & \multicolumn{2}{|c|}{168} & 82 & 250 & 171 & 579 \\
\hline \multicolumn{12}{|c|}{ Palha } \\
\hline \multicolumn{6}{|c|}{ Macronutrientes } & \multicolumn{6}{|c|}{ Micronutrientes } \\
\hline $\mathrm{N}$ & $\mathrm{P}$ & $\mathrm{K}$ & $\mathrm{Ca}$ & \multicolumn{2}{|l|}{$\mathrm{Mg}$} & \multicolumn{2}{|l|}{$\mathrm{B}$} & $\mathrm{Cu}$ & $\mathrm{Fe}$ & $\mathrm{Mn}$ & $\mathrm{Zn}$ \\
\hline \multicolumn{6}{|c|}{------------------------------- $\mathrm{g} \mathrm{kg}^{-1}$------------------------------ } & \multicolumn{6}{|c|}{-------------------------------------- $\mathrm{mg} \mathrm{kg}^{-1}$------------------------------------ } \\
\hline 10,9 & 1,3 & 13,5 & 3,5 & \multicolumn{2}{|l|}{1,6} & \multicolumn{2}{|c|}{4,9} & 1,9 & 349 & 202 & 18,0 \\
\hline \multicolumn{12}{|c|}{ Vinhaça } \\
\hline $\mathrm{K}$ & $\mathrm{Ca}$ & $S$ & $\mathrm{MO}$ & $\mathrm{C}$ org. & $\mathrm{N}$ & jeldahl & $n$ & ature & Umidade & $\mathrm{P}$ & $\mathrm{Mg}$ \\
\hline --------- & ----- & $-------g$ & $J^{-1}-\cdot-\cdot$ & -------- & 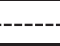 & --------- & pil & malura & $\%$ & --------- mg & $L^{-1}$--------- \\
\hline 1,31 & 1,46 & 1,2 & 29,0 & 16,9 & & 1,9 & & 4 & 95,9 & 10,6 & 362 \\
\hline -------- & & 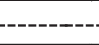 & & - Micror & nutr & entes --- & . & 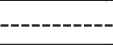 & 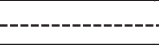 & ----------- & \\
\hline B & $\mathrm{Cu}$ & $\mathrm{Fe}$ & $\mathrm{Mn}$ & $\mathrm{Zn}$ & & $\mathrm{Cd}$ & & $\mathrm{Cr}$ & $\mathrm{Ni}$ & $\mathrm{Pb}$ & $\begin{array}{l}\text { Kelaçao } \\
\text { CAN }\end{array}$ \\
\hline --------. & - & - & - & ----- m & $\mathrm{g} \mathrm{L}^{-1}$ & ----------. & & - & ----. & - & \\
\hline 0,04 & 0,58 & 36,4 & 10,8 & 2,1 & & $<0,0$ & & 0,02 & $<0,01$ & 0,32 & 10,6 \\
\hline
\end{tabular}

1. As siglas $\mathrm{MO}, \mathrm{SB}, \mathrm{CTC}$ e V\% referem-se, respectivamente, a teor de matéria orgânica, soma por bases, capacidade de troca catiônica e saturação por bases.

Tabela 2 - Tratamentos empregados no experimento e as respectivas legendas

\begin{tabular}{|l|c|}
\hline \multicolumn{1}{|c|}{ Tratamento } & Legenda \\
\hline Controle & $\mathrm{C}$ \\
\hline Apenas palha & $\mathrm{P}$ \\
\hline Apenas vinhaça & $\mathrm{V}$ \\
\hline Apenas o herbicida imazapic & $\mathrm{H}$ \\
\hline Palha + vinhaça & $\mathrm{PV}$ \\
\hline Palha + herbicida imazapic & $\mathrm{PH}$ \\
\hline Herbicida + vinhaça antes do herbicida & $\mathrm{HVa}$ \\
\hline Herbicida + vinhaça depois do herbicida & $\mathrm{HVd}$ \\
\hline $\begin{array}{l}\text { Herbicida }+ \text { vinhaça aplicada junto com o } \\
\text { herbicida }\end{array}$ & $\mathrm{HVj}$ \\
\hline Palha + herbicida + vinhaça antes do herbicida & $\mathrm{PHVa}$ \\
\hline Palha + herbicida + vinhaça depois do herbicida & $\mathrm{PHVd}$ \\
\hline $\begin{array}{l}\text { Palha }+ \text { herbicida }+ \text { vinhaça aplicada junto com o } \\
\text { herbicida }\end{array}$ & $\mathrm{PHVj}$ \\
\hline
\end{tabular}

que a vinhaça foi aplicada junto com o herbicida $(\mathrm{HVj})$, o imazapic foi diluído em água até $1 / 4$ do volume necessário e depois completado com vinhaça. Vinte e oito dias após a aplicação dos herbicidas, a palha dos vasos foi retirada, contou-se o número das brotações e mediu-se a altura das plantas de tiririca. As partes aéreas foram cortadas no nivel do solo, lavadas em água corrente para retirada de partículas de solo, secas em papel-toalha e avaliaram-se suas biomassas frescas. A parte subterrânea da tiririca foi lavada, separada nas diferentes estruturas, contou-se o número de tubérculos e avaliaram-se as biomassas frescas de raiz e de tubérculos.

Após a pesagem dos tubérculos, aqueles que não apresentaram raízes e rizomas foram avaliados com relação à viabilidade total. Para isso, os tubérculos foram colocados sobre duas camadas de papel-substrato especial, tipo mata-borrão, umedecidas até a saturação com água destilada (3,0 $\mathrm{ml} \mathrm{g}^{-1}$ de substrato seco), dentro de caixas plásticas tipo gerbox, cujas medidas eram $0,11 \times 0,11 \times 0,035 \mathrm{~m}$, que foram mantidas em germinadores verticais tipo BOD reguladas à temperatura alternada de 20$30^{\circ} \mathrm{C}\left(20^{\circ} \mathrm{C}-16 \mathrm{~h} / 30^{\circ} \mathrm{C}-8 \mathrm{~h}\right)$, em presença de 
luz (aproximadamente 1.000 lux) no período de temperatura mais alta. Após 13 dias nessas condições, foi contado o número de tubérculos brotados. Considerou-se como brotado o tubérculo que emitiu um broto com um centímetro ou mais de comprimento. A viabilidade dos tubérculos não-brotados foi determinada pelo teste de tetrazólio (Delouche et al., 1962). Para isso, os tubérculos foram cortados longitudinalmente ao meio e uma das metades foi embebida em solução $0,1 \%$ de cloreto de trifeniltetrazólio por $4-6$ horas, em câmara a $40^{\circ} \mathrm{C}$, até o desenvolvimento de característica cor vermelha ou rosada, cuja intensidade, usada na classificação de um tubérculo como viável ou não, foi comparada com a de uma amostrapadrão, composta por tubérculos sabidamente viáveis e testados da mesma forma. Os tubérculos não-viáveis apresentavam-se com coloração rosa-pálida (em comparação com a amostra-padrão), em alguns tratamentos havia áreas incolores, ou totalmente escurecidas, quase pretas, ou estes estavam inteiramente chochos. A porcentagem de viabilidade total consistiu da soma de tubérculos brotados e daqueles classificados como viáveis pelo teste do tetrazólio.

As partes aéreas, as raízes e os tubérculos foram colocados para secar em estufa sob ventilação forçada a $65-70{ }^{\circ} \mathrm{C}$ até atingir massa constante, quando se determinaram suas biomassas secas. Os tubérculos que não apresentaram crescimento, após o teste de tetrazólio, foram secos e avaliaram-se também suas biomassas secas.

O efeito dos tratamentos foi analisado estatisticamente, empregando-se o teste $\mathrm{F}$ na análise da variância, e as médias, quando significativas, foram comparadas pelo teste de Scheffé, o qual foi escolhido por não exigir que os contrastes sejam ortogonais e não haver número máximo de contrastes a serem analisados (Pimentel Gomes, 1976). Foram avaliados os seguintes contrastes: controle $\mathrm{x}$ tratamentos com herbicidas $(\mathrm{C} \times \mathrm{H})$; controle $\mathrm{x}$ tratamentos com palha $(\mathrm{C} \times \mathrm{P})$; controle $\mathrm{x}$ tratamentos com vinhaça $(\mathrm{C} \times \mathrm{V})$; sem herbicida $\mathrm{x}$ com herbicida ( $\mathrm{SH} \times \mathrm{CH}$ ); sem palha $\mathrm{x}$ com palha (SP x CP); sem vinhaça $x$ com vinhaça (SV x CV); HVa x HVd; HVa x HVj; HVd x HVj; HVa x PHVa; HVd x PHVd; HVj x PHVj; PHVa x PHVd; PHVa x PHVj; e PHVd x PHVj. Os índices empregados na análise estatística dos diferentes contrastes são apresentados na Tabela 3. Os valores das variâncias para cada variável, quando positivos, indicam que o primeiro fator analisado é superior ao segundo, e, quando negativo, o segundo é superior ao primeiro (Tabelas 5 a 7 ).

\section{RESULTADOS E DISCUSSÃO}

\section{Efeito dos tratamentos com imazapic}

Quando se comparou o controle (sem palha, sem vinhaça e sem herbicida) com os tratamentos em que foi aplicado imazapic $(\mathrm{C} \times \mathrm{CH})$, verificou-se que houve diferença estatística para altura das plantas e viabilidade dos tubérculos de tiririca (Tabela 5). O controle apresentou plantas de tiririca com maior estatura e viabilidade dos tubérculos que os tratamentos com imazapic. Hernandez et al. (2001) observaram que em tratamentos com imazapic houve redução na altura das plantas de tiririca, comparado com o controle. Herbicidas que inviabilizam tubérculos de tiririca, quando absorvidos nas folhas ou na solução do solo, garantem melhor desempenho para que haja desinfestação gradativa da área (Durigan et al., 2005).

Em todas as variáveis analisadas, os tratamentos sem imazapic apresentaram valores superiores aos daqueles com o produto ( $\mathrm{SH} \mathrm{x}$ $\mathrm{CH})$, demonstrando sua eficácia no controle do crescimento inicial da tiririca (Tabelas 5, 6 e 7$)$.

\section{Efeito da palha}

A viabilidade dos tubérculos foi maior no controle do que sob cobertura com palha $(\mathrm{Cx}$ $\mathrm{CP})$ (Tabela 5). A presença da cobertura morta deixada sobre o solo afeta a quantidade de radiação solar incidente e a qualidade do comprimento de ondas luminosas, mantendo a temperatura menos oscilante (Fenner, 1980), o que dificulta a emergência das plântulas (Teasdale et al., 1991). A brotação das gemas dos tubérculos da tiririca é altamente dependente da temperatura, sendo mais rápida e completa em ambientes com temperaturas alternadas que sob constantes (Miles et al., 1996).

Planta Daninha, Viçosa-MG, v. 26, n. 2, p. 439-449, 2008 
Tabela 3 - Índices empregados nos diferentes tratamentos para os contrastes analisados. Campinas-SP, 2003

\begin{tabular}{|c|c|c|c|c|c|c|c|c|c|c|c|c|c|c|c|}
\hline \multirow{2}{*}{ Trat. } & \multicolumn{15}{|c|}{ Número do contraste } \\
\hline & 1 & 2 & 3 & 4 & 5 & 6 & 7 & 8 & 9 & 10 & 11 & 12 & 13 & 14 & 15 \\
\hline $\mathrm{C}$ & 8 & 6 & 8 & 2 & 1 & 2 & 0 & 0 & 0 & 0 & 0 & 0 & 0 & 0 & 0 \\
\hline $\mathrm{H}$ & -1 & 0 & 0 & $1-$ & 1 & 2 & 0 & 0 & 0 & 0 & 0 & 0 & 0 & 0 & 0 \\
\hline P & 0 & -1 & 0 & 2 & -1 & 2 & 0 & 0 & 0 & 0 & 0 & 0 & 0 & 0 & 0 \\
\hline V & 0 & 0 & -1 & 2 & 1 & -1 & 0 & 0 & 0 & 0 & 0 & 0 & 0 & 0 & 0 \\
\hline PH & -1 & -1 & 0 & -1 & -1 & 2 & 0 & 0 & 0 & 0 & 0 & 0 & 0 & 0 & 0 \\
\hline PV & 0 & -1 & -1 & 2 & -1 & -1 & 0 & 0 & 0 & 0 & 0 & 0 & 0 & 0 & 0 \\
\hline $\mathrm{HVa}$ & -1 & 0 & -1 & -1 & 1 & -1 & 1 & 1 & 0 & 1 & 0 & 0 & 0 & 0 & 0 \\
\hline $\mathrm{HVd}$ & -1 & 0 & -1 & -1 & 1 & -1 & -1 & 0 & 1 & 0 & 1 & 0 & 0 & 0 & 0 \\
\hline $\mathrm{HVj}$ & -1 & 0 & -1 & -1 & 1 & -1 & 0 & -1 & -1 & 0 & 0 & 1 & 0 & 0 & 0 \\
\hline PHVa & -1 & -1 & -1 & -1 & -1 & -1 & 0 & 0 & 0 & -1 & 0 & 0 & 1 & 1 & 0 \\
\hline PHVd & -1 & -1 & -1 & -1 & -1 & -1 & 0 & 0 & 0 & 0 & -1 & 0 & -1 & 0 & 1 \\
\hline PHVj & -1 & -1 & -1 & -1 & -1 & -1 & 0 & 0 & 0 & 0 & 0 & -1 & 0 & -1 & -1 \\
\hline
\end{tabular}

1) controle $\mathrm{x}$ tratamentos com herbicidas; 2) controle $\mathrm{x}$ tratamentos com palha; 3) controle $\mathrm{x}$ tratamentos com vinhaça; 4) sem herbicida $\times$ com herbicida; 5) sem palha $\mathrm{x}$ com palha; 6) sem vinhaça $\mathrm{x}$ com vinhaça; 7) herbicida + vinhaça antes da aplicação do herbicida (HVa) x herbicida + vinhaça depois da aplicação do herbicida (HVd); 8) herbicida + vinhaça antes da aplicação do herbicida (HVa) x herbicida + vinhaça aplicada junto com o herbicida (HVj); 9) herbicida + vinhaça depois da aplicação do herbicida (HVd) $\mathrm{x}$ herbicida + vinhaça aplicada junto com o herbicida $(\mathrm{HVj}) ; 10)$ herbicida + vinhaça antes da aplicação do herbicida $(\mathrm{HVa}) \times \mathrm{x}$ palha + herbicida + vinhaça antes do herbicida (PHVa); 11) herbicida + vinhaça depois da aplicação do herbicida (HVd) x palha + herbicida + vinhaça depois do herbicida (PHVd); 12) herbicida + vinhaça aplicada junto com o herbicida (HVj) x palha + herbicida + vinhaça aplicada junto com o herbicida $(\mathrm{PHVj})$; 13) palha + herbicida + vinhaça antes do herbicida (PHVa) x palha + herbicida + vinhaça depois do herbicida (PHVd); 14) palha + herbicida + vinhaça antes do herbicida (PHVa) x palha + herbicida + vinhaça aplicada junto com o herbicida (PHVj); e 15) palha + herbicida + vinhaça depois do herbicida (PHVd) x palha + herbicida + vinhaça aplicada junto com o herbicida $(\mathrm{PHVj})$

Tabela 4 - Valores médios das variáveis: número de tubérculos (Ntub), número de brotações (Nbrot), biomassas frescas de raiz (BFR), da parte aérea (BFPA) e de tubérculos (BFT), altura média de plantas, biomassas secas de raiz (BSR), da parte aérea (BSPA) e de tubérculos (BST) e viabilidade dos tubérculos por tratamento. Médias de quatro repetições. Campinas-SP, 2003

\begin{tabular}{|c|c|c|c|c|c|c|c|c|c|c|}
\hline \multirow{2}{*}{ Trat. } & \multirow{2}{*}{$\mathrm{Ntub}^{\underline{1}}$} & \multirow{2}{*}{$\operatorname{Nbrot}^{1 /}$} & BFR & BFPA & BFT & \multirow{2}{*}{$\begin{array}{c}\text { Altura } \\
\mathrm{cm}\end{array}$} & BSR & BSPA & BST & \multirow{2}{*}{$\begin{array}{c}\text { Viabilidade }^{2} \\
\%\end{array}$} \\
\hline & & & \multicolumn{3}{|c|}{-------------- g vaso ${ }^{-1}$------------- } & & \multicolumn{3}{|c|}{-------------- g vaso ${ }^{-1}$-------------- } & \\
\hline$C^{-3 /}$ & 7,1 & 5,46 & 10,43 & 6,75 & 3,65 & 18,88 & 0,94 & 1,15 & 1,13 & 100,00 \\
\hline $\mathrm{H}$ & 4,1 & 0,00 & 0,00 & 0,00 & 3,11 & 0,00 & 0,00 & 0,00 & 1,17 & 38,67 \\
\hline $\mathrm{P}$ & 7,5 & 6,49 & 9,91 & 3,97 & 3,93 & 14,11 & 0,74 & 0,71 & 1,21 & 100,00 \\
\hline $\mathrm{V}$ & 19,1 & 21,41 & 40,54 & 36,87 & 10,49 & 21,68 & 5,24 & 6,03 & 2,19 & 100,00 \\
\hline $\mathrm{PH}$ & 4,2 & 3,20 & 2,36 & 1,40 & 3,75 & 13,09 & 0,22 & 0,27 & 1,32 & 60,94 \\
\hline $\mathrm{PV}$ & 15,9 & 21,40 & 38,65 & 47,37 & 6,16 & 23,27 & 4,51 & 6,74 & 1,00 & 100,00 \\
\hline $\mathrm{HVa}$ & 4,0 & 0,00 & 2,13 & 0,00 & 2,05 & 0,00 & 0,18 & 0,00 & 0,61 & 51,97 \\
\hline $\mathrm{HVd}$ & 4,0 & 0,00 & 0,76 & 0,00 & 2,81 & 0,00 & 0,05 & 0,00 & 0,96 & 34,65 \\
\hline $\mathrm{HVj}$ & 15,6 & 12,71 & 26,21 & 29,14 & 6,16 & 12,00 & 2,99 & 3,76 & 0,99 & 38,95 \\
\hline $\mathrm{PHVa}$ & 9,2 & 6,33 & 27,98 & 23,12 & 3,42 & 14,16 & 2,77 & 2,94 & 0,61 & 34,60 \\
\hline PHVd & 4,0 & 3,74 & 1,82 & 0,90 & 2,86 & 11,88 & 0,24 & 0,18 & 1,01 & 49,61 \\
\hline $\mathrm{PHVj}$ & 9,0 & 22,32 & 22,51 & 30,41 & 3,12 & 19,75 & 2,04 & 3,86 & 0,40 & 43,47 \\
\hline
\end{tabular}

1. Dados transformados em $\sqrt{x}$ para análise estatística, mas na tabela são apresentados os valores originais. 2. Dados transformados em arc sen $\sqrt{\mathrm{X} / 100}$ para análise estatística, mas na tabela são apresentados os valores originais. $3 . \mathrm{C}=$ controle; $\mathrm{H}=$ tratamento com imazapic; $\mathrm{P}=$ tratamento com palha; $\mathrm{V}$ $=$ tratamento com vinhaça; $\mathrm{PH}=$ palha + herbicida; $\mathrm{PV}=$ palha + vinhaça; $\mathrm{HVa}=$ herbicida + vinhaça antes da aplicação do herbicida; $\mathrm{HVd}=$ herbicida + vinhaça depois da aplicação do herbicida; $\mathrm{HVj}=$ herbicida + vinhaça aplicada junto com o herbicida; $\mathrm{PHVa}=$ palha + herbicida + vinhaça antes do herbicida; $\mathrm{PHVd}=$ palha + herbicida + vinhaça depois do herbicida; $\mathrm{PHVj}=$ herbicida + vinhaça aplicada junto com o herbicida 
Tabela 5 - Valores e variâncias dos contrastes para número de tubérculo e de brotações, altura média de plantas e viabilidade do tubérculo. Campinas-SP, 2003

\begin{tabular}{|c|c|c|c|c|c|c|c|c|}
\hline \multirow[b]{2}{*}{ Contraste } & \multicolumn{2}{|c|}{ Número de tubérculo ${ }^{1 / /}$} & \multicolumn{2}{|c|}{ Número de brotaçãa ${ }^{1 /}$} & \multicolumn{2}{|c|}{ Altura média planta } & \multicolumn{2}{|c|}{ 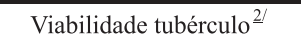 } \\
\hline & $\begin{array}{l}\text { Valor do } \\
\text { contraste }\end{array}$ & $\begin{array}{c}\text { Variância do } \\
\text { constraste }\end{array}$ & $\begin{array}{l}\text { Valor do } \\
\text { contraste }\end{array}$ & $\begin{array}{c}\text { Variância do } \\
\text { constraste }\end{array}$ & $\begin{array}{l}\text { Valor do } \\
\text { contraste }\end{array}$ & $\begin{array}{c}\text { Variância do } \\
\text { constraste }\end{array}$ & $\begin{array}{l}\text { Valor do } \\
\text { contraste }\end{array}$ & $\begin{array}{c}\text { Variância do } \\
\text { constraste }\end{array}$ \\
\hline $\mathrm{CxCH}^{3 /}$ & 1,235 & $2,152^{\text {ns }}$ & 4,172 & $1,345^{\mathrm{ns}}$ & 80,128 & $65,834^{*}$ & 387,326 & $1237,9^{*}$ \\
\hline $\mathrm{C} \times \mathrm{CP}$ & $-0,858$ & $1,255^{\text {ns }}$ & $-4,111$ & $0,785^{\text {ns }}$ & 16,995 & $38,40^{\mathrm{ns}}$ & 186,577 & $722,11^{*}$ \\
\hline $\mathrm{C} \times \mathrm{CV}$ & $-3,062$ & $2,152^{\mathrm{ns}}$ & $-3,294$ & $1,345^{\mathrm{ns}}$ & 48,267 & $65,834^{*}$ & 297,097 & $1237,9^{*}$ \\
\hline $\mathrm{SH} \times \mathrm{CH}$ & 7,466 & $0,717^{*}$ & 13,751 & $0,448^{*}$ & 84,994 & $21,945^{*}$ & 387,326 & $412,64 *$ \\
\hline $\mathrm{SP} \times \mathrm{CP}$ & 0,166 & $0,358^{\text {ns }}$ & $-7,604$ & $0,224 *$ & $-43,705$ & $10,97^{\mathrm{ns}}$ & $-14,173$ & $206,32^{\mathrm{ns}}$ \\
\hline $\mathrm{SV} \times \mathrm{CV}$ & $-5,423$ & $0,717^{*}$ & $-8,648$ & $0,448^{*}$ & $-10,588$ & $21,95^{\text {ns }}$ & 116,639 & $206,32 *$ \\
\hline HVax HVd & 0,000 & $0,060^{\mathrm{ns}}$ & 0,000 & $0,037^{\mathrm{ns}}$ & 0,000 & $1,829^{\mathrm{ns}}$ & 10,070 & $34,38^{\text {ns }}$ \\
\hline $\mathrm{HVa} \times \mathrm{HVj}$ & $-1,948$ & $0,060^{*}$ & $-3,565$ & $0,037^{*}$ & $-12,000$ & $1,829 *$ & 7,514 & $34,38^{\mathrm{ns}}$ \\
\hline $\mathrm{HVd} \times \mathrm{HVj}$ & $-1,948$ & $0,060^{*}$ & $-3,565$ & $0,037 *$ & $-12,000$ & $1,829^{*}$ & $-2,556$ & $34,38^{\mathrm{ns}}$ \\
\hline HVaxPHVa & $-1,030$ & $0,060^{\mathrm{ns}}$ & $-2,516$ & $0,037^{*}$ & $-14,160$ & $1,829^{*}$ & 10,098 & $34,38^{\mathrm{ns}}$ \\
\hline HVdxPHVd & 0,000 & $0,060^{\text {ns }}$ & $-1,933$ & $0,037^{*}$ & $-11,878$ & $1,829^{*}$ & $-8,765$ & $34,38^{\text {ns }}$ \\
\hline HVjx PHVj & 0,948 & $0,060^{\mathrm{ns}}$ & $-1,159$ & $0,037^{*}$ & $-7,750$ & $1,829^{*}$ & $-2,636$ & $34,38^{\text {ns }}$ \\
\hline PHVaxPHVd & 1,030 & $0,060^{\mathrm{ns}}$ & 0,583 & $0,037^{\text {ns }}$ & 2,283 & $1,829^{\mathrm{ns}}$ & $-8,793$ & $34,38^{\text {ns }}$ \\
\hline PHVaxPHVj & 0,030 & $0,060^{\mathrm{ns}}$ & $-2,208$ & $0,037 *$ & $-5,590$ & $1,829^{\mathrm{ns}}$ & $-5,220$ & $34,38^{\mathrm{ns}}$ \\
\hline PHVdxPHVj & $-1,001$ & $0,060^{\mathrm{ns}}$ & $-2,791$ & $0,037^{*}$ & $-7,873$ & $1,829^{*}$ & 3,573 & $34,38^{\mathrm{ns}}$ \\
\hline
\end{tabular}

ns $=$ constraste não-significativo. ${ }^{*}=$ contraste significativo a $5 \%$. 1. Dados transformados em $\sqrt{x}$ para análise estatística, mas na tabela são apresentados os valores originais. 2. Dados transformados em arc sen $\sqrt{x} / 100$ para análise estatística. 3. Contrastes analisados: 1) controle $x$ tratamentos com herbicidas; 2) controle $\mathrm{x}$ tratamentos com palha; 3) controle $\mathrm{x}$ tratamento com vinhaça; 4) sem herbicida $\mathrm{x}$ com herbicida; 5) sem palha x com palha; 6) sem vinhaça x com vinhaça; 7) herbicida + vinhaça antes da aplicação do herbicida (HVa) $\mathrm{x}$ herbicida + vinhaça depois da aplicação do herbicida (HVd); 8) herbicida + vinhaça antes da aplicação do herbicida (HVa) x herbicida + vinhaça aplicada junto com o herbicida (HVj); 9) herbicida + vinhaça depois da aplicação do herbicida (HVd) x herbicida + vinhaça aplicada junto com o herbicida $(\mathrm{HVj}) ; 10)$ herbicida + vinhaça antes da aplicação do herbicida (HVa) x palha + herbicida + vinhaça antes do herbicida (PHVa); 11) herbicida + vinhaça depois da aplicação do herbicida (HVd) x palha + herbicida + vinhaça depois do herbicida (PHVd); 12) herbicida + vinhaça aplicada junto com o herbicida $(\mathrm{HVj}) \times$ palha + herbicida + vinhaça aplicada junto com o herbicida $(\mathrm{PHVj}) ; 13)$ palha + herbicida + vinhaça antes do herbicida (PHVa) $\mathrm{x}$ palha + herbicida + vinhaça depois do herbicida (PHVd); 14) palha + herbicida + vinhaça antes do herbicida (PHVa) x palha + herbicida + vinhaça aplicada junto com o herbicida (PHVj); e 15) palha + herbicida + vinhaça depois do herbicida (PHVd) x palha + herbicida + vinhaça aplicada junto com o herbicida $(\mathrm{PHVj})$.

Em condições normais de cultivo, em áreas sem palha, as oscilações térmicas são maiores e é mais comum ocorrer estresse hídrico que sob condições em que o solo se mantém com cobertura. Em razão do estresse hídrico e de maiores temperaturas, a tiririca pode entrar em dormência ou mesmo ter sua viabilidade afetada. No presente experimento não houve estresse hídrico, pois, sempre que necessário, os vasos foram irrigados. Assim, no controle houve maior incidência de luz, maiores oscilações térmicas e tempo de exposição à temperatura máxima que sob palha, o que aumentou a viabilidade dos tubérculos.

Segundo Arévalo \& Bertoncini (1999), a palhada de cana-de-açúcar deixada sobre o solo pode controlar mais de $50 \%$ das espécies daninhas que infestam esta cultura, devido a efeitos físicos e bioquímicos. No presente caso, acredita-se que, por ser um experimento de curta duração, o efeito foi mais físico que bioquímico, pois 28 dias após o plantio dos tubérculos a degradação da palha era ainda incipiente. Com o sombreamento causado pela palha de cana-de-açúcar, a brotação da tiririca pode desaparecer, mas os tubérculos permanecem viáveis e, quando removido o obstáculo, ocorre rápida reinfestação (Miles et al., 1996).

Comparando os tratamentos sem e com adição de palha ao solo (SP x CP), observou-se que o número de brotações (Tabela 5) e a biomassa fresca da parte aérea (Tabela 6) foram maiores nos tratamentos $\mathrm{CP}$, porém a viabilidade dos tubérculos foi maior naqueles SP (Tabela 5). Os resultados diferem daqueles obtidos por Gomide (1993), que observou menor incidência de plantas daninhas quando a palha de cana-de-açúcar foi deixada sobre o solo. No experimento, o aumento no teor de umidade do solo deve ter sido a principal causa do aumento no número de brotação, pois, segundo Adams (1966), em solo coberto, ocorre redução significativa da evaporação durante o período mais quente do dia mesmo em períodos sem 
Tabela 6 - Valores e variâncias dos contrastes para biomassas frescas de raiz (BFR), parte aérea (BFPA) e de tubérculos (BFT). Campinas-SP, 2003

\begin{tabular}{|l|c|c|c|c|c|c|}
\hline \multirow{2}{*}{ Contraste } & \multicolumn{2}{|c|}{ BFR } & \multicolumn{2}{c|}{ BFPA } & \multicolumn{2}{c|}{ BFT } \\
\cline { 2 - 7 } & $\begin{array}{c}\text { Valor do } \\
\text { contraste }\end{array}$ & $\begin{array}{c}\text { Variância do } \\
\text { constraste }\end{array}$ & $\begin{array}{c}\text { Valor do } \\
\text { contraste }\end{array}$ & $\begin{array}{c}\text { Variância do } \\
\text { constraste }\end{array}$ & $\begin{array}{c}\text { Valor do } \\
\text { contraste }\end{array}$ & $\begin{array}{c}\text { Variância do } \\
\text { constraste }\end{array}$ \\
\hline $\mathrm{C} \mathrm{x} \mathrm{CH}^{1 /}$ & $-0,370$ & $348,454^{\text {ns }}$ & $-30,970$ & $306,821^{\text {ns }}$ & 1,883 & $15,916^{\text {ns }}$ \\
\hline C x CP & $-40,678$ & $203,265^{\text {ns }}$ & $-66,667$ & $178,979^{*}$ & $-1,365$ & $9,285^{\text {ns }}$ \\
\hline C x CV & $-77,190$ & $348,454^{\text {ns }}$ & $-113,812$ & $306,821^{*}$ & $-7,905$ & $15,916^{\text {ns }}$ \\
\hline SH x CH & 115,270 & $116,151^{*}$ & 104,945 & $102,274^{*}$ & 21,148 & $5,305^{*}$ \\
\hline SP x CP & $-23,165$ & $58,076^{\text {ns }}$ & $-34,407$ & $51,137^{*}$ & 5,020 & $2,653^{\text {ns }}$ \\
\hline SV x CV & $-115,190$ & $116,15^{*}$ & $-143,582$ & $102,274^{*}$ & $-8,215$ & $5,305^{\text {ns }}$ \\
\hline HVa x HVd & 1,373 & $9,679^{\text {ns }}$ & 0,000 & $8,523^{\text {ns }}$ & $-0,755$ & $0,442^{\text {ns }}$ \\
\hline HVa x HVj & $-24,078$ & $9,679^{*}$ & $-29,138$ & $8,523^{*}$ & $-4,108$ & $0,442^{*}$ \\
\hline HVd x HVj & $-25,450$ & $9,679^{*}$ & $-29,138$ & $8,523^{*}$ & $-3,353$ & $0,442^{*}$ \\
\hline HVa x PHVa & $-25,848$ & $9,679^{*}$ & $-23,122$ & $8,523^{*}$ & $-1,375$ & $0,442^{\text {ns }}$ \\
\hline HVd x PHVd & $-1,055$ & $9,679^{\text {ns }}$ & $-0,900$ & $8,523^{\text {ns }}$ & $-0,058$ & $0,442^{\text {ns }}$ \\
\hline HVj x PHVj & 3,700 & $9,679^{\text {ns }}$ & $-1,275$ & $8,523^{\text {ns }}$ & 3,035 & $0,442^{\text {ns }}$ \\
\hline PHVa xHVd & 26,165 & $9,679^{*}$ & 22,222 & $8,523^{*}$ & 0,563 & $0,442^{\text {ns }}$ \\
\hline PHVa xHVj & 5,470 & $9,679^{\text {ns }}$ & $-7,290$ & $8,523^{\text {ns }}$ & 0,303 & $0,442^{\text {ns }}$ \\
\hline PHVd x PHVj & $-20,695$ & $9,679^{*}$ & $-29,513$ & $8,523^{*}$ & $-0,260$ & $0,442^{\text {ns }}$ \\
\hline
\end{tabular}

ns $=$ constraste não-significativo. ${ }^{*}=$ contraste significativo a $5 \%$. 1 . Contrastes analisados: 1) controle $\mathrm{x}$ tratamentos com herbicidas; 2 ) controle $\mathrm{x}$ tratamentos com palha; 3) controle $\mathrm{x}$ tratamento com vinhaça; 4) sem herbicida $\mathrm{x}$ com herbicida; 5) sem palha $\mathrm{x}$ com palha; 6) sem vinhaça $\mathrm{x}$ com vinhaça; 7) herbicida + vinhaça antes da aplicação do herbicida (HVa) x herbicida + vinhaça depois da aplicação do herbicida (HVd); 8) herbicida + vinhaça antes da aplicação do herbicida (HVa) x herbicida + vinhaça aplicada junto com o herbicida (HVj); 9) herbicida + vinhaça depois da aplicação do herbicida (HVd) x herbicida + vinhaça aplicada junto com o herbicida $(\mathrm{HVj}) ; 10)$ herbicida + vinhaça antes da aplicação do herbicida (HVa) x palha + herbicida + vinhaça antes do herbicida (PHVa); 11) herbicida + vinhaça depois da aplicação do herbicida (HVd) x palha + herbicida + vinhaça depois do herbicida (PHVd); 12) herbicida + vinhaça aplicada junto com o herbicida (HVj) x palha + herbicida + vinhaça aplicada junto com o herbicida (PHVj); 13) palha + herbicida + vinhaça antes do herbicida (PHVa) x palha + herbicida + vinhaça depois do herbicida (PHVd); 14) palha + herbicida + vinhaça antes do herbicida (PHVa) x palha + herbicida + vinhaça aplicada junto com o herbicida (PHVj); e 15) palha + herbicida + vinhaça depois do herbicida (PHVd) x palha + herbicida + vinhaça aplicada junto com o herbicida $(\mathrm{PHVj})$

precipitação, reduzindo a necessidade de irrigação. Durante o período chuvoso, além de a palha aumentar a infiltração, há ainda aumento no movimento descendente do excesso de água.

\section{Efeito da vinhaça}

A aplicação da vinhaça ao solo reduziu a altura média das plantas e a viabilidade dos tubérculos (Tabela 5), porém aumentou as biomassas fresca e seca da parte aérea e a biomassa seca de raiz, quando comparada com o tratamento controle (Tabelas 6 e 7). Como resultado da adição da vinhaça ao solo, além de ocorrer elevação do $\mathrm{pH}$ e do teor de matéria orgânica, pode ter havido ainda aumento da disponibilidade de alguns nutrientes, do poder de retenção de cátions e da capacidade de retenção de água, estimulando também a atividade microbiana do solo (Quintela et al., 2002), o que pode explicar o estímulo do desenvolvimento da raiz e da parte aérea das plantas de tiririca. A viabilidade dos tubérculos foi maior no controle (Tabela 5), demonstrando que a vinhaça afeta a brotação da tiririca; entretanto, Voll (2005), obteve maior emergência da tiririca com esse resíduo.

Sengik et al. (1996), pesquisando o efeito de doses de vinhaça em dois tipos de solo no crescimento de sorgo granifero, verificaram que após 30 dias de incubação e sob condições favoráveis de temperatura e umidade a aplicação desse resíduo provocou acréscimos na produção de matéria seca de raízes e da parte aérea. Segundo Voll (2005), o efeito da vinhaça mostrou-se mais acentuado nos primeiros sete dias após a sua aplicação. Esse fato está provavelmente associado à rápida deterioração das suas moléculas, sobretudo das substâncias alelopáticas, em decorrência da ação dos microrganismos e dos efeitos da temperatura, da incidência luminosa e do $\mathrm{pH}$, principalmente. 
Tabela 7 - Valores e variâncias dos contrastes para biomassas secas de raiz (BSR), parte aérea (BSPA) e de tubérculos (BST) Campinas-SP, 2003

\begin{tabular}{|c|c|c|c|c|c|c|}
\hline \multirow[b]{2}{*}{ Contraste } & \multicolumn{2}{|c|}{ BFR } & \multicolumn{2}{|c|}{ BFPA } & \multicolumn{2}{|c|}{ BFT } \\
\hline & $\begin{array}{l}\text { Valor do } \\
\text { contraste }\end{array}$ & $\begin{array}{l}\text { Variância do } \\
\text { constraste }\end{array}$ & $\begin{array}{l}\text { Valor do } \\
\text { contraste }\end{array}$ & $\begin{array}{c}\text { Variância do } \\
\text { constraste }\end{array}$ & $\begin{array}{l}\text { Valor do } \\
\text { contraste }\end{array}$ & $\begin{array}{l}\text { Variância do } \\
\text { constraste }\end{array}$ \\
\hline $\mathrm{C} \times \mathrm{CH}^{1 /}$ & $-0,944$ & $4,150^{\mathrm{ns}}$ & $-1,785$ & $6,278^{\mathrm{ns}}$ & 1,945 & $1,866^{\mathrm{ns}}$ \\
\hline $\mathrm{C} \times \mathrm{CP}$ & $-4,853$ & $2,421^{\mathrm{ns}}$ & $-7,788$ & $3,661^{\mathrm{ns}}$ & 1,210 & $1,089^{\mathrm{ns}}$ \\
\hline $\mathrm{C} \times \mathrm{CV}$ & $-10,466$ & $4,150^{*}$ & $-14,288$ & $6,177^{*}$ & 1,238 & $1,866^{\mathrm{ns}}$ \\
\hline $\mathrm{SH} \times \mathrm{CH}$ & 14,356 & $1,383^{*}$ & 18,265 & $2,092^{*}$ & 3,980 & $0,622^{*}$ \\
\hline SP x CP & $-1,111$ & $0,692^{\mathrm{ns}}$ & $-3,765$ & $1,046^{\mathrm{ns}}$ & 1,493 & $0,311^{\mathrm{ns}}$ \\
\hline $\mathrm{SV} \times \mathrm{CV}$ & $-14,211$ & $1,383^{*}$ & $-19,243$ & $2,092^{*}$ & 1,858 & $0,622^{\mathrm{ns}}$ \\
\hline $\mathrm{HVa} \times \mathrm{HVd}$ & 0,129 & $0,115^{\mathrm{ns}}$ & 0,000 & $0,174^{\mathrm{ns}}$ & $-0,358$ & $0,052^{\mathrm{ns}}$ \\
\hline $\mathrm{HVa} \times \mathrm{HVj}$ & $-2,815$ & $0,115^{*}$ & $-3,758$ & $0,174^{*}$ & $-0,358$ & $0,052^{\mathrm{ns}}$ \\
\hline $\mathrm{HVd} \times \mathrm{HVj}$ & $-2,944$ & $0,115^{*}$ & $-3,758$ & $0,174^{*}$ & $-0,028$ & $0,052^{\mathrm{ns}}$ \\
\hline HVa x PHVa & $-2,590$ & $0,115^{*}$ & $-2,938$ & $0,174^{*}$ & $-0,005$ & $0,052^{\mathrm{ns}}$ \\
\hline HVd x PHVd & $-0,189$ & $0,115^{\mathrm{ns}}$ & $-0,180$ & $0,174^{\mathrm{ns}}$ & $-0,045$ & $0,052^{\mathrm{ns}}$ \\
\hline $\mathrm{HVj} \times \mathrm{PHVj}$ & 0,953 & $0,115^{\mathrm{ns}}$ & $-0,105$ & $0,174^{\mathrm{ns}}$ & 0,590 & $0,052^{\mathrm{ns}}$ \\
\hline PHVa x PHVd & 2,530 & $0,115^{*}$ & 2,758 & $0,174^{*}$ & $-0,398$ & $0,052^{\mathrm{ns}}$ \\
\hline PHVa x PHVj & 0,728 & $0,115^{\mathrm{ns}}$ & $-0,925$ & $0,174^{\mathrm{ns}}$ & 0,210 & $0,052^{\mathrm{ns}}$ \\
\hline PHVd x PHVj & $-1,803$ & $0,115^{*}$ & $-3,683$ & $0,174^{*}$ & 0,608 & $0,052^{\mathrm{ns}}$ \\
\hline
\end{tabular}

$\mathrm{ns}=$ constraste não-significativo. ${ }^{*}=$ contraste significativo a $5 \%$. 1. Contrastes analisados: 1) controle $\mathrm{x}$ tratamentos com herbicidas; 2) controle $\mathrm{x}$ tratamentos com palha; 3) controle $\mathrm{x}$ tratamento com vinhaça; 4) sem herbicida $\mathrm{x}$ com herbicida; 5) sem palha $\mathrm{x}$ com palha; 6) sem vinhaça $\mathrm{x}$ com vinhaça; 7) herbicida + vinhaça antes da aplicação do herbicida (HVa) x herbicida + vinhaça depois da aplicação do herbicida (HVd); 8) herbicida + vinhaça antes da aplicação do herbicida (HVa) x herbicida + vinhaça aplicada junto com o herbicida (HVj); 9) herbicida + vinhaça depois da aplicação do herbicida (HVd) x herbicida + vinhaça aplicada junto com o herbicida $(\mathrm{HVj}) ; 10)$ herbicida + vinhaça antes da aplicação do herbicida (HVa) x palha + herbicida + vinhaça antes do herbicida (PHVa); 11) herbicida + vinhaça depois da aplicação do herbicida (HVd) x palha + herbicida + vinhaça depois do herbicida (PHVd); 12) herbicida + vinhaça aplicada junto com o herbicida (HVj) x palha + herbicida + vinhaça aplicada junto com o herbicida $(\mathrm{PHVj}) ; 13)$ palha + herbicida + vinhaça antes do herbicida $(\mathrm{PHVa}) \mathrm{x}$ palha + herbicida + vinhaça depois do herbicida $(\mathrm{PHVd}) ; 14)$ palha + herbicida + vinhaça antes do herbicida (PHVa) x palha + herbicida + vinhaça aplicada junto com o herbicida (PHVj); e 15) palha + herbicida + vinhaça depois do herbicida (PHVd) x palha + herbicida + vinhaça aplicada junto com o herbicida (PHVj).

\section{Efeito do meio de aplicação da vinhaça}

Nos tratamentos sem palha, não houve diferença entre aplicação da vinhaça antes ou depois do imazapic (HVa $\mathrm{xHVd}$ ) nas diferentes variáveis analisadas (Tabelas 4 a 7). Quando foi aplicada a vinhaça misturada com o imazapic, tanto em relação à aplicação antes como depois do herbicida (HVa x HVj e HVd x HVj), verificou-se que esse procedimento reduziu a ação do produto, aumentando o número de tubérculos e de brotações, a altura média das plantas de tiririca (Tabela 5) e as biomassas frescas e secas da raiz e da parte aérea (Tabelas 6 e 7). Também a biomassa fresca de tubérculos foi maior nesse tratamento (Tabela 6).

De acordo com Buss (1977), a prática de misturar herbicidas com outros defensivos agrícolas e mesmo fertilizantes, visando normalmente $o$ aspecto econômico das aplicações, pode determinar sinergismo, antagonismo ou indiferença na ação do produto, quando comparada à ação isolada. Esse autor relatou ainda que, quando se mistura herbicida em soluções nitrogenadas, quanto menor a porcentagem de ingrediente ativo do produto e quanto mais eficiente o surfatante e outros componentes do produto formulado, menor o efeito adverso em dispersar a estabilidade da solução. Por outro lado, se a molaridade da solução nitrogenada era aumentada, ocorria diminuição sensivel da estabilidade da dispersão dos herbicidas. De acordo com Prata \& Lavorenti (2000), quando qualquer tipo de material orgânico é adicionado a um solo em que foi aplicado um determinado herbicida, esse material pode influenciar de duas maneiras o comportamento da molécula: aumentando a sorção do herbicida, indisponibilizando-o ou ativando a microbiota do solo e, assim, promovendo aumento de sua degradação.

Comparando o tratamento sem e com patha quando foi aplicada vinhaça antes do 
herbicida (HVa x PHVa), verificou-se que a adição de palha beneficiou o número de brotações e a altura média de plantas (Tabela 5), bem como as biomassas frescas e secas de raiz e da parte aérea (Tabelas 6 e 7). Entretanto, quando se compararam os tratamentos sem e com palha com as aplicações de vinhaça depois do herbicida (HVd $x$ PHVd) ou usando a vinhaça misturada com o imazapic ( $\mathrm{HVj}$ x PHVj), observou-se que apenas o número de brotações e a altura média das plantas (Tabela 5) foram afetados, apresentando valores superiores no tratamento com palha.

O estímulo ao desenvolvimento da tiririca quando sob palha e com adição da vinhaça misturada com o herbicida ( $\mathrm{PHVj}$ ) deve ter sido decorrente do efeito desse resíduo no solo. Embora a vinhaça apresente características ácidas, com pH em torno de 4,0, sua adição ao solo provoca aumento no $\mathrm{pH}$. Essa elevação do $\mathrm{pH}$ é conseqüência do efeito da matéria orgânica da vinhaça, grande parte na forma coloidal, que, quando adicionada ao solo, complexa o aluminio deste, além de introduzir cátions básicos, conduzindo o $\mathrm{pH}$ a niveis mais próximos da alcalinidade (Silva \& Silva, 1986).

O imazapic, por ser fracamente adsorvido em solos com $\mathrm{pH}$ mais elevado, pode ser mais facilmente perdido por lixiviação (Vencill, 2002). A sorção é um processo interfacial e refere-se à adesão ou atração de uma ou mais camadas iônicas ou moleculares para uma superficie (Prata \& Lavorenti, 2000). Segundo Piccolo et al. (1996), a sorção entre um herbicida e substâncias orgânicas pode variar, dependendo da estrutura macromolecular e da dimensão dessas substâncias, podendo causar redução na ação do produto.

Nos tratamentos com palha e com aplicação de vinhaça antes e depois do imazapic (PHVa x PHVd), verificou-se que, quando foi aplicada vinhaça antes do herbicida, foram obtidos valores maiores de biomassas frescas e secas de raiz e da parte aérea (Tabelas 6 e 7). Comparando os tratamentos com palha e com vinhaça antes do herbicida e em mistura com o imazapic (PHVa x PHVj), verificou-se que o tratamento com palha aumentou o número de brotações de tiririca (Tabela 4) e a biomassa seca da parte aérea, reduzindo a ação do imazapic (Tabela 7).
Comparando os tratamentos com palha e com aplicação de vinhaça depois do herbicida ou em mistura com imazapic (PHVd $\mathrm{x} P H V j$ ), observou-se que este último prejudicou o controle da tiririca, pois o número de brotações, a altura média das plantas e as biomassas frescas e secas da raiz e da parte aérea foram maiores (Tabelas 5 a 7).

Concluiu-se que o imazapic foi eficiente no controle da tiririca quando comparado com a testemunha. A aplicação isolada da vinhaça ou a adição de apenas a palha ao solo estimularam o crescimento da tiririca, embora tenham reduzido a viabilidade dos tubérculos. Sem palha, não houve diferença no desenvolvimento da tiririca quando a aplicação de vinhaça foi feita antes ou depois do imazapic. Entretanto, quando em mistura com a vinhaça, o produto não controlou a tiririca. A presença da palha no tratamento onde foi aplicada vinhaça antes do herbicida reduziu a ação do imazapic, em comparação com aquele sem palha. O número de brotações e a altura média de plantas de tiririca foram maiores nos tratamentos com palha quando foi aplicado imazapic depois ou mesmo junto com a vinhaça. Sob palha, a aplicação de vinhaça após o herbicida ou em mistura com imazapic aumentou apenas o número de brotações.

\section{LITERATURA CITADA}

ADAMS, J. E. Influence of mulches on runoff, erosion, and soil moisture depletion. Soil Sci. Soc. Am. Proc., v. 30, p. 110-114, 1966.

ARÉVALO, R. A.; BERTONCINI, E. I. Manejo químico de plantas daninhas nos resíduos de colheita de cana crua.

STAB, v. 17, n. 1, p. 36-38, 1999.

BLEVINS, R. L. et al. Influence of no-tillage on soil moisture. Agron. J., v. 63, n. 4, p. 593-596, 1971.

BUSS, A. Viabilidade do uso de herbicidas em mistura com vinhaça em soqueiras de cana-de-açúcar. 1977. $68 \mathrm{f}$. Dissertação (Mestrado em Solos e Nutrição de Plantas) Escola Superior de Agricultura Luiz de Queiroz, Piracicaba, 1977.

BUSS, A.; SILVA, S. A. Aplicação dos herbicidas oryzalin e tebuthiuron em mistura com vinhaça em cana soca. In: SEMINÁRIO BRASILEIRO DE HERBICIDAS E ERVAS DANINHAS, 11., 1976, Londrina. Resumos... Londrina: Sociedade Brasileira de Herbicidas e Ervas Daninhas, 1976. p. 65-66. 
CHRISTOFFOLETI, P. J.; BACCHI, O. O. S. Efeito da aplicação de vinhaça sobre a população e controle químico das plantas daninhas na cultura da cana-de-açúcar

(Saccharum spp). Planta Daninha, v. 8, n. 1/2, p. 60-70, 1985.

DELOUCHE, J. C.; STILL, T. W.; LIENHARD, M. The tetrazolium test for seed viability. Mississippi State College/ Mississippi Agricultural Experiment Station, 1962, 63 p. (Technical Bulletin, 51).

DURIGAN, J. C.; CORREIA, N. M.; TIMOSSI, P. C. Estádios de desenvolvimento e vias de contato e absorção dos herbicidas na inviabilização de tubérculos de Cyperus rotundus. Planta Daninha, v. 23, n. 4, p. 621-626, 2005.

FENNER, M. Germination tests on thirty-two East African weed species. Weed Res., v. 20, n. 1, p. 135-138, 1980.

GOMIDE, M. B. Potencialidades alelopáticas dos restos culturais de dois cultivares de cana-de-açúcar (Saccharum spp.), no controle de algumas plantas daninhas. 1993. 96 f. Tese (Doutoramento em Fitotecnia) Escola Superior de Agricultura Luiz de Queiroz, Piracicaba, 1993.

HERNANDEZ, D. D.; ALVES, P. L. C. A.; MARTINS, J. V. F. Influência do resíduo de colheita de cana-de-açúcar sem queima sobre a eficiência dos herbicidas imazapic e imazapic + pendimethalin. Planta Daninha, v. 19, n. 3, p. 419-426, 2001.

HOLM, L. G. et al. The world's worst weeds: distribution and biology. Honolulu: University Press Hawaii, 1977. $609 \mathrm{p}$.

KISSMAN, K. G. Plantas infestantes e nocivas. 2.ed. São Paulo: Basf, 1997. v. 1. p. 222-229.

MEDEIROS, D. Efeitos da palha de cana-de-açúcar (Saccharum spp.) sobre o manejo de plantas daninhas e dinâmica do banco de sementes. 2001.126 f. Dissertação (Mestrado em Agronomia) - Universidade de São Paulo, Piracicaba, 2001

MILES, J. E.; NISHIMOTO, R. K.; KAWABATA, O. Diurnally alternating temperatures stimulate sprouting of purple nutsedge (Cyperus rotundus) tubers. Weed Sci., v. 44, p. 122-125, 1996.

NAQUIN, B. J. Herbicide retention as affected by sugarcane mulch residue. 2005. $67 \mathrm{f}$. Thesis (Master of Science of the Department of Agronomy and Environmental Management) - Louisiana State University and Agricultural and Mechanical College, Lafayette, 2005.

NOVO, M. C. S. S. et al. Efeito da palha de cana-de-açúcar e do tamanho dos tubérculos na biomassa das estruturas subterrâneas de Cyperus rotundus. Planta Daninha, v. 23, n. 3, p. 437-448, 2005.

PIMENTEL GOMES, F. Curso de estatística experimental. Piracicaba: Nobel, 1976. p. 4446.
PICCOLO, A. et al. Adsorption of glyphosate by humic substances. J. Agric. Food Chem., v. 44, n. 2, p. 24422446, 1996.

PRATA, F. ; LAVORENTI, A. Comportamento de herbicida no solo: influência da matéria orgânica. R. Bioc., v. 6, n. 2 , p. 17-22, 2000.

QUINTELA, A. C. R. et al. Controle de plantas daninhas em cana crua (cultivar RB835089) no sistema integrado palhiço, herbicida e vinhaça. STAB, v. 20, n. 4, p. 38-42, 2002.

RODELLA, A. A.; FERRARI, S. R. A composição da vinhaça e efeitos de sua aplicação como fertilizante na canade-açúcar. Brasil Açuc., v. 90, n. 1, p. 380-387, 1997.

RODRIGUES, B. N.; ALMEIDA, F. S. Guia de herbicidas. 5.ed. Londrina: 2005. 592 p.

SÃO PAULO. Decreto no 47.700: Regulamenta a Lei noำ 11.241, de 19 de setembro de 2002, que dispõe sobre a eliminação gradativa da queima da palha da cana-de-açúcar e dá providências correlatas. Diário Oficial do Estado de São Paulo. 11 de março de 2003. 6 p.

SENGIK, E. et al. Efeitos da vinhaça sobre o crescimento do sorgo granífero. In: UNIVERSIDADE ESTADUAL DE MARINGÁ - Centro de Ciências Agrárias. Anuário 1995/ 1996. Maringá: 1996. p. 163-166.

SILVA, M. A.; SILVA, G. L. Utilização agrícola da vinhaça e demais efluentes líquidos. Álcool Açúcar, n. 31, p. 12-25, 1986.

TEASDALE, J. R.; BESTE, C. E.; POTTS, W. E. Response of weeds to tillage and cover crop residue. Weed Sci., v. 39, n.1, p. 195-199, 1991.

TREZZI, M. M.; VIDAL, R. A. Potencial de utilização de cobertura vegetal de sorgo e milheto na supressão de plantas daninhas em condição de campo: II - Efeitos da cobertura morta. Planta Daninha, v. 22, n. 1, p. 1-10, 2004.

VELINI, E. D.; NEGRISOLI, E. Controle de plantas daninhas em canacrua. In: CONGRESSO BRASILEIRO DA CIÊNCIA DAS PLANTAS DANINHAS, 22., 2000, Fóz do Iguaçú. Palestras... Londrina: Sociedade Brasileira da Ciência das Plantas Daninhas, 2000. p. 148-164.

VENCILL, W. K. (Ed.) Herbicide Handbook. 2002. Lawrence: Weed Science Society of América, 2002. 493 p.

VOLL, C. E. Aplicação de vinhaça e do extrato de palhiço de cana-de-açúcar no controle de plantas daninhas. 2005. 45 f. Dissertação (Mestrado em Fitotecnia) - Escola Superior de Agricultura Luiz de Queiroz, Piracicaba, 2005. 